\title{
A Comparison of the Relative Sensitivity of Structural and Functional Cellular Responses in the Alga Chlamydomonas eugametos Exposed to the Herbicide Paraquat
}

\author{
D. Franqueira, A. Cid, E. Torres, M. Orosa, C. Herrero \\ Laboratorio de Microbiología, Departamento de Biología Celular y Molecular, Facultad de \\ Ciencias, Universidade da Coruña, Campus da Zapateira s/n. 15071 A Coruña, Spain, ES
}

Archives of Environmental Contamination and Toxicology

April 1999, Volume 36, Issue 3, pp 264-269

Received: 29 May 1998/Accepted: 12 October 1998

DOI $10.1007 / \mathrm{s} 002449900470$

\begin{abstract}
.
The effect of the herbicide paraquat on the freshwater microalga Chlamydomonas eugametos was studied in function of different parameters such as growth, elemental composition, total lipids, and photosynthetic pigments content and others assayed by flow cytometry (cell viability, cell volume, and granularity). The study reveals that paraquat concentrations above $0.15 \mu \mathrm{M}$ are toxic for the microalga $C$. eugametos, inducing an inhibition of all the physiological parameters analyzed and strong structural changes. However, lower concentrations cause alterations in certain cellular components that are especially sensitive to the toxic action of the herbicide; so total lipids and photosynthetic pigments content are affected by concentrations such low as $0.037 \mu \mathrm{M}$. Taking into account these results, these parameters are better indicators of the cellular state than data on biomass or growth rate.
\end{abstract}


Currently, the most commonly used ecotoxicity test for screening aquatic pollutants is the shortterm fish lethality test, which has been recently criticized (Fentem and Balls 1993); the alternatives to this test include the use of "lower" organisms such as bacteria and microalgae (the United Kingdom's Animals (Scientific Procedures) Act 1986 and EC Directive 86/609/EEC legislation). Microalgae have been recognized as useful indicators of environmental quality (Ho"rnstro"m 1990); simple bioassays conducted in the laboratory using microalgae can provide valuable information about the possible disruptive effects of pesticides on algal morphology and physiology (Blaise 1993).

Aquatic environments, including fresh water, estuaries, and coastal marine waters, are often contaminated with numerous organic and inorganic compounds, including herbicides. Paraquat (1,18-dimethyl-4,48-bipyridilium dichloride) is a nonselective herbicide widely used to prevent the growth of broad leaf weeds and grasses, mainly in railways and roadsides (Kalayanova and El Batawi 1991). This quaternary ammonium compound is a cationic species in aqueous solution, and after application, this chemical can be adsorbed into the soil or transported to the aquatic environment by runoff or leaching (Ibáñez et al. 1996). Information on the influence of this chemical on the lowest levels of the food chain is scarce (Ibrahim 1990; Bray et al. 1993; Saenz et al. 1997).

The mode of action of paraquat, as a competitive inhibitor of photosynthetic electron transport at PS I level (Summers 1980; Devine et al. 1993), makes it potentially lethal to a wide variety of nontarget species of primary producers, including phytoplankton and benthic algae. Paraquat in cells leads to the generation of free oxygen radicals. These free oxygen radicals cause lipid peroxidation damaging cell membranes and leading to cell death (Tissut et al. 1987). Free radical scavengers, such as carotenoids, are rapidly overwhelmed due to the efficiency of paraquat in generating free radicals.

The test species chosen for this study was the freshwater microalga Chlamydomonas eugametos. Different parameters for microalgal activity show widely different sensitivities to aquatic pollutants. The present work examines the effect of paraquat on parameters commonly used in microalgal toxicity assays, such as growth and biochemical composition. Since flow cytometry could be considered useful in the monitoring of the physiological state of microalgal cells (Cid et al. 1995, 1996), other parameters assayed by flow cytometry, such as cellular viability, volume, and granularity, were examined. 


\section{Materials and Methods}

Chlamydomonas eugametos Moewus (Chlamydomonadaceae) was obtained from the Department of Pure and Applied Ecology of the University of Amsterdam (The Netherlands); it was cultured in Bristol medium (Brown et al. 1967). Cultures were carried out in Pyrex glass bottles containing $500 \mathrm{ml}$ of medium, after having been autoclaved at $121^{\circ} \mathrm{C}$ for $20 \mathrm{~min}$. Microalgal cultures were maintained at $18 \pm 1^{\circ} \mathrm{C}$ and $68.25 \mu \mathrm{mol}$ photon $\mathrm{m}^{-2} \mathrm{~s}^{-1}$, with a dark:light cycle of $12: 12 \mathrm{~h}$. Initial density was $1 \times 10^{5}$ cells $\mathrm{ml}^{-1}$.

Paraquat concentrations assayed were $0.037,0.075,0.15,0.30$, and $0.60 \mu \mathrm{M}$; stock solutions were prepared by dissolving granulated herbicide paraquat (Sigma, MW: 257.2) in distilled and sterilized water. In addition to these, control cultures without paraquat were also included. All experiments were carried out in triplicate for $96 \mathrm{~h}$ as has already been indicated for toxicity assays with microalgae (Walsh and Merril 1984).

Growth of the microalgal cultures was measured by counting daily culture aliquots in a Neubauer hemocytometer, and growth rates were expressed in doublings day $^{-1}$. The most common parameter used in toxicity assays is the $\mathrm{EC}_{50}$, i.e., the concentration of the tested substance that decreases the growth by $50 \%$. In order to obtain a confidence interval for the $E_{50}$ value, probit analysis of the growth data was carried out using the SPSS-PC + software (SPSS Inc.).

Viability, cellular volume, and granularity were determined using flow cytometric techniques. Aliquots of microalgal cultures were analyzed in a FACScan flow cytometer (Becton Dickinson Instruments), equiped with an argon excitation laser (488 nm). Chlorophyll a red fluorescence was used to set the gating level, excluding particles without red fluorescence, which are obviously nonalgal particles. Viability was measured by incubation of culture aliquots for 5-10 min at room temperature with propidium iodide $(\mathrm{PI})$ at a final concentration of $60 \mu \mathrm{M}$ (Abalde et al. 1995); this compound stains nonviable cells and if excited by blue light, it gives off orange fluorescence (530-560 nm) that was measured in the flow cytometer. Since an increase in the forward light scatter (FSC) signal can be correlated with an increase in cell volume and an increase in side light scatter (SSC) signal can be correlated with an increase in cell granularity (revised by Shapiro [1995]), aliquots of microalgal cultures stained with PI were analyzed to study the possible changes in cell volume and granularity; only viable cells were analyzed for both cell parameters.

For each cytometric parameter investigated, at least $10^{4}$ cells were analyzed per culture and fluorescence measurements were expressed in a logarithmic scale. Data collection was performed using the list mode. The means of forward and side scatter signal were provided by the instrument software (LYSIS II program; Becton Dickinson Instruments). Data on the forward and side scatter signal of the cells, related to cell volume and granularity, were expressed as a percentage of the control cells signal according to the equation of Reader et al. (1993): 
$\% P=100-\left[100\left(P_{c}-P_{t}\right) / P_{c}\right]$

where \% $\mathrm{P}$ is the percentage of the FSC or SSC signal of $C$. eugametos cells; $\mathrm{P}_{\mathrm{c}}$ is the mean FSC or SSC signal of control cells; and $\mathrm{P}_{\mathrm{t}}$ is the mean FSC or SSC signal of paraquat-treated cells.

Samples for biochemical analysis were taken after $96 \mathrm{~h}$ of paraquat exposure. The algal cells were harvested by centrifugation and frozen at $-70^{\circ} \mathrm{C}$ prior to liophilization for $24 \mathrm{~h}$. The dry weight was determined according to Vonshak (1986). Carbon and nitrogen content were determined with an elemental analyzer (Carlo Erba CHNS-O 1108). Total lipids were determined gravimetrically after chloroformmethanol (2:1) extraction using the Bligh and Dyer method (Bligh and Dyer 1959).

Photosynthetic pigments were determined from spectrophotometric measurements of $90 \%$ acetone extracts using the equations of Jeffrey and Humphrey (1975) for chlorophylls, and Strickland and Parsons (1972) for total carotenoids.

Data were statistically analyzed by an overall one-way analysis of variance (ANOVA), and, when differences observed were significant, means were compared by the multiple range Duncan test, at a level of significance of $0.05(p<0.05)$.

\section{Results}

Growth

Paraquat affected the growth of the freshwater microalga $C$. eugametos (Figure 1, Table 1). There were significant differences in growth between control cultures and those cultures exposed to paraquat concentration higher than $0.075 \mu \mathrm{M} \quad(\mathrm{p}<0.05)$, whereas lower concentrations did not provoke significant differences in comparison with control cultures (Figure 1).

Maximum growth rates (0.77-0.84 doublings day $\left.^{-1}\right)$ were obtained in cultures treated with paraquat doses lower than $0.15 \mu \mathrm{M}$; higher paraquat concentrations inhibited the growth of this microalga (Table 1). The $\mathrm{EC}_{50}$ of paraquat for growth, calculated by probit analysis, was 0.28 $\mu \mathrm{M}$ after $96 \mathrm{~h}$ of the herbicide exposure. Experimental confirmation of this theorical value was carried out, and the experimental results are into the confidence interval of the statistical analysis. 


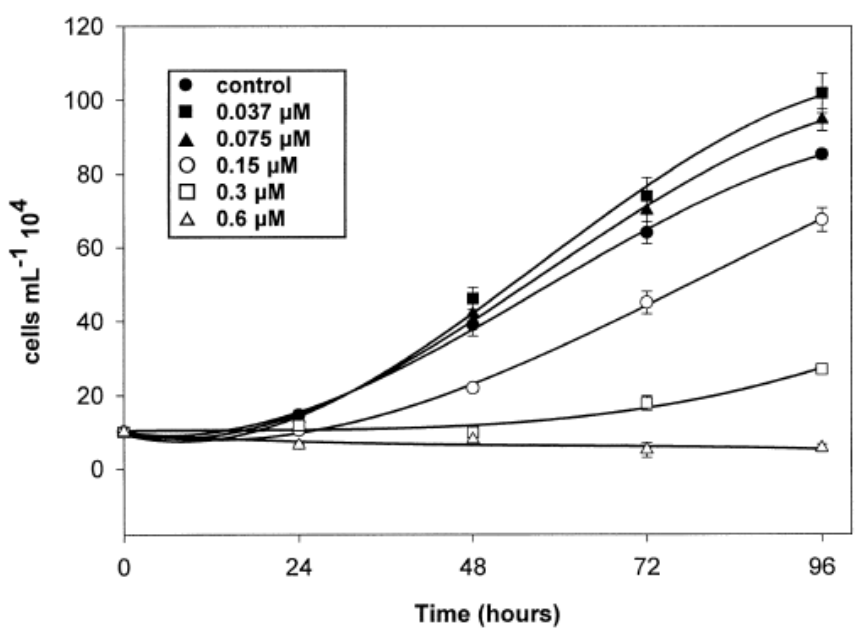

Fig. 1. Growth curves (expressed as cells $3104 \mathrm{ml}^{-1}$ ) of cultures of Chlamydomonas eugametos exposed to different paraquat concentrations (expressed as $\mu \mathrm{M}$ )

\section{Cellular Viability}

After $96 \mathrm{~h}$ of paraquat exposure, the proportion of viable cells in control cultures was $99 \%$; paraquat concentrations of 0.30 and $0.60 \mu \mathrm{M}$ provoked a decrease of this parameter in comparison to the control ( $85 \%$ and $37 \%$ cellular viability, respectively) (Table 1 ). Cellular viability decrease observed in $0.60 \mu \mathrm{M}$ cultures can be related to the strong inhibition observed in the growth data (Table 1).

\section{Forward Scatter (FSC) and Side Scatter (SSC)}

Paraquat provoked an increase in the FSC signal, related to an increase of cell volume, of $C$. eugametos cells after $96 \mathrm{~h}$ of exposure to this herbicide. The highest concentrations tested $(0.30$ and $0.60 \mu \mathrm{M})$ caused higher increases of this signal (47 and $74 \%$, respectively) in comparison with control cultures (Figure 2).

An increase in the SSC signal, related to an increase in the internal cellular granularity was also observed (Figure 2). After $96 \mathrm{~h}$ of paraquat exposure, paraquat concentrations of 0.30 and 0.60 $\mu \mathrm{M}$ caused a drastic increase in the internal cellular granularity $(63 \%$ and $309 \%$ respectively, with respect to the control) (Figure 2).

\section{Dry Weight and Elemental Composition}

Cellular dry weight (DW) after $96 \mathrm{~h}$ of paraquat exposure showed a significant increase at paraquat concentrations higher than $0.15 \mu \mathrm{M}(\mathrm{p}, 0.05)$, being $545.4 \mathrm{pg}$ per cell in cultures exposed to a paraquat concentration of $0.60 \mu \mathrm{M}$, nearly five times greater than the cellular DWof the control cultures (117.8 $\mathrm{pg} \mathrm{cell}^{-1}$ ) (Table 1).

Carbon and nitrogen percentages in the dry biomass, determined after $96 \mathrm{~h}$ of culture, showed that the $\mathrm{C} / \mathrm{N}$ ratio increased significantly $(\mathrm{p}, 0.05)$ in cultures with $0.15,0.30$, and $0.60 \mu \mathrm{M}(5.10$, 5.31 , and 6.76, respectively) in comparison with the ratio obtained in control cultures (4.88) (Table 1). 
Total lipid content in biomass presented a significant decrease, with respect to the lipid content in the control cultures (170.1 $\mathrm{mg} \mathrm{g}^{-1}$ dry weight), in all cultures exposed to paraquat concentration higher than $0.037 \mu \mathrm{M}$; minimum lipid content was obtained in cultures with 0.60 $\mu \mathrm{M}$ paraquat (90 $\mathrm{mg} \mathrm{g}^{-1}$ dry weight), which showed nearly a $50 \%$ decrease with respect to the controls (Figure 3 ).

Photosynthetic pigment content (chlorophyll $a, b$, and total carotenoids) showed changes after $24 \mathrm{~h}$ of paraquat exposure, but maximum differences with respect to the control occurred after $96 \mathrm{~h}$ of treatment. Chlorophylls were more sensitive to paraquat toxicity than total carotenoid (Figure 4). After $96 \mathrm{~h}$ of treatment, chlorophyll content decreased as paraquat concentration increased, showing values of $33.2 \mathrm{mg}$ of chlorophyll $a$ and $8.2 \mathrm{mg}$ of chlorophyll $b$ per gram of dry weight in control cultures and values of $5.3 \mathrm{mg}$ of chlorophyll $a$ and $2.4 \mathrm{mg}$ of chlorophyll $b$ per gram of dry weight in cultures with $0.60 \mu \mathrm{M}$ paraquat (Figure 4).

Similar pattern occurred in carotenoid content; control cultures showed a carotenoid content value of $9.8 \mathrm{mg} \mathrm{g}^{-1}$ dry weight. Paraquat concentrations of 0.30 and $0.60 \mu \mathrm{M}$ reduced the carotenoid content significantly $(p<0.05): 0.30 \mu \mathrm{M}$ of paraquat reduced the carotenoid content by half, and $0.60 \mu \mathrm{M}$ reduced the carotenoid content seven times compared to the control culture (Figure 4).

Table 1. Growth rate (expressed as doublings day $^{-1}$ ), percentage

\begin{tabular}{lclll}
$\begin{array}{l}\text { Paraquat } \\
(\mu \mathrm{M})\end{array}$ & $\begin{array}{l}\text { Growth Rate }(\mu) \\
\text { (doublings day }^{-1} \text { ) }\end{array}$ & $\begin{array}{l}\text { Cell } \\
\text { Viability } \\
(\%)\end{array}$ & $\begin{array}{l}\text { Dry Weight } \\
\left(\text { pg cell }^{-1}\right)\end{array}$ & C/N \\
\hline 0 & $0.77 \pm 0.06$ & 99 & $117.80 \pm 0.59$ & $4.88 \pm 0.02$ \\
0.037 & $0.84 \pm 0.02$ & 99 & $105.03 \pm 3.93$ & $4.82 \pm 0.04$ \\
0.075 & $0.81 \pm 0.01$ & 98 & $104.10 \pm 0.53$ & $4.84 \pm 0.02$ \\
0.15 & $0.69 \pm 0.03$ & 95 & $100.30 \pm 9.26$ & $5.10 \pm 0.02$ \\
0.3 & $0.36 \pm 0.05$ & 85 & $200.90 \pm 3.72$ & $5.31 \pm 0.05$ \\
0.6 & $-0.22 \pm 0.06$ & 37 & $545.40 \pm 7.33$ & $6.76 \pm 0.15$
\end{tabular}

of cell viability, dry weight (expressed as pg cell ${ }^{-1}$ ), and carbon/nitrogen ratio obtained in cultures of Chlamydomonas eugametos exposed to different paraquat concentrations (expressed as $\mu \mathrm{M}$ ) after $96 \mathrm{~h}$ 
Fig. 2. Forward and side scatter signal (FSC and SSC) of the Chlamydomonas eugametos cells at different paraquat concentrations (expressed as $\mu \mathrm{M})$, after 96 h. Data are expressed as the percentage of the control cells signal (arbitrary units) according to the equation of Reader et al. (1993)

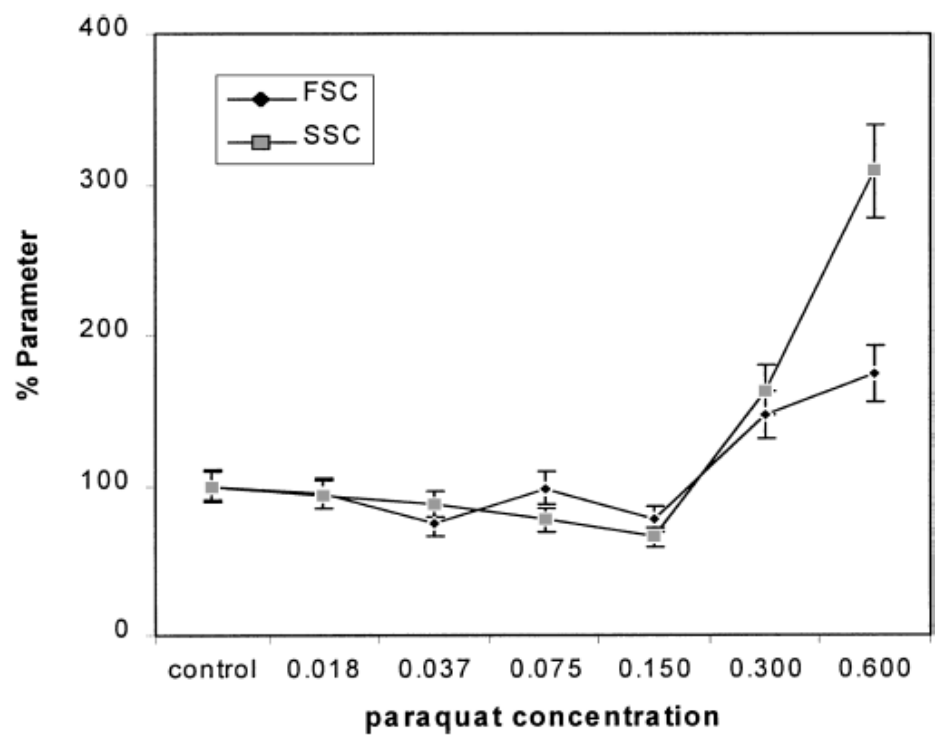

\section{Discussion}

Many classes of compounds can exhibit environmental toxicity. One of the most commonly discussed and researched are the pesticides, which are introduced into aquatic ecosystems from agricultural runoff (Landis and Yu 1995). Two bipyridyl herbicides, paraquat (methyl viologen) and diquat, have been in global use for over 30 years.

The results obtained in the present work indicate that paraquat affects the growth of $C$. eugametos at concentrations of $0.15 \mu \mathrm{M}$ or higher. Other experiments performed on Chlamydomonas reinhardtii showed that there was an obvious growth reduction by $0.10 \mu \mathrm{M}$ paraquat and that the growth was completely inhibited at concentrations of $0.30 \mu \mathrm{M}$ (Bray et al. 1993). Therefore, the paraquat concentrations $\left(1 \mathrm{mg} \mathrm{L}^{-1}\right)$ allowable for controlling of macrophytes in freshwater fish farms (Ibrahim 1990) are clearly growth inhibitory for the test photosynthetic microorganism $C$. eugametos.

The inhibitory effect of paraquat on growth only at the highest concentrations assayed could be explained on the existence of detoxifying mechanisms in the cells. Low paraquat concentrations could induce oxidative stress that would lead to an increase in the activity of specific enzymes involved in the detoxification (superoxide dismutase, glutation reductase) as observed in the microalgae C. reinhardtii (Bray et al. 1993) and Chlorella (Rabinowitch et al. 1983). The cells would be able to tolerate the presence of certain herbicide concentrations without significant effects on growth. However, these mechanisms would not be effective against the higher herbicide concentrations since paraquat, in the presence of light, accelerates the production of species of active oxygen (Bray et al. 1993). The defense mechanisms would be overcome, and the cells could undergo deleterious effects brought about by the high levels of superoxide radicals and the formation of hydrogene peroxide (Kirtikara and Talbot 1996). 
The $E_{50}$ value for inhibition of growth obtained at $96 \mathrm{~h}$ of exposure to paraquat $(0.28 \mu \mathrm{M})$ is in accordance with the measurements for cell viability using FCM techniques, which showed a decrease in cell viability in cultures with the highest doses of paraquat assayed ( $85 \%$ in cultures with $0.30 \mu \mathrm{M}$ paraquat and only $37 \%$ of cell viability with $0.60 \mu \mathrm{M}$ paraquat).

The calculated $\mathrm{EC}_{50}$ values for the reduction of growth of Scenedesmus dimorphus and Ankistrodesmus falcatus were 39.8 and $93.3 \mu \mathrm{g} \mathrm{L}^{-1}$, respectively (Ibrahim 1990); the value that we have obtained for $C$. eugametos $\left(72.0 \mu \mathrm{g} \mathrm{L}^{-1}\right.$, equivalent to $\left.0.28 \mu \mathrm{M}\right)$ indicates that $C$. eugametos is quite tolerant to the herbicide paraquat. The differences between results could be due to species differences. Different species can respond to the same pesticide in different ways (Ibrahim 1990).

The increase of cellular dry weight at the highest concentrations of paraquat assayed is related with the inhibitory effect on growth; in these cultures, cells formed palmelloid colonies (clusters of nonflagellated cells closed in a common wall), observed by light microscopy. Several factors can induce the formation of these structures in Chlamydomonas (Iwasa and Murakami 1968; 1969; Nakamura et al. 1976; Olsen et al. 1983). Palmelloid colonies became attached to the walls of the culture vessel and subsequently showed a much slower growth rate than nonpalmelloid vegetative cells.

In this way, the increase in the cellular volume of $C$. eugametos detected by FCM in the cultures treated with 0.30 and $0.60 \mu \mathrm{M}$ paraquat (Figure 2) could be related to palmelloid colony formation, probably due to the incapacity to finish cell division as well as failures of regulation of cellular volume because of the of membranes as a consequence of the high levels of oxidative radicals formed. Bray et al. (1993), using transmission electron microscopy techniques, detected that cultures with $0.075 \mu \mathrm{M}$ paraquat showed a small proportion of cells swollen and that they were less electron-dense than the normal cells, suggesting an increase in the cell moisture. At $0.15 \mu \mathrm{M}$ paraquat, the proportion of cells with lower electrondensity had increased considerably and at $0.30 \mu \mathrm{M}$, all the cells appeared swollen and were of low electron-density. These authors stated that in addition to the swelling and the low cellular electrondensity observed as a consequence of paraquat addition, other ultrastructural alterations were present that could explain the increase in the granularity that was detected using FCM at $96 \mathrm{~h}$ of culture. Among the alterations that were observed in cells containing severe damages, they indicated the presence of multivesicular bodies in the cytoplasm that seemed to originate from polyribosomal complexes and endoplasmic reticulum ribosomes; the free ribosomes would decrease in number and appear aggregated; the plasma membrane was often discontinous and separated from the cell wall, and so on. Using transmission electron microscopy (unpublished data) we can confirm the presence of palmelloid structures, as well as numerous structural changes. 
Fig. 3. Total lipid content, expressed as $\mathrm{mg}$ per $\mathrm{g}$ of dry weight, extracted from cultures of Chlamydomonas eugametos exposed to different paraquat concentrations (expressed as $\mu \mathrm{M})$, after $96 \mathrm{~h}$

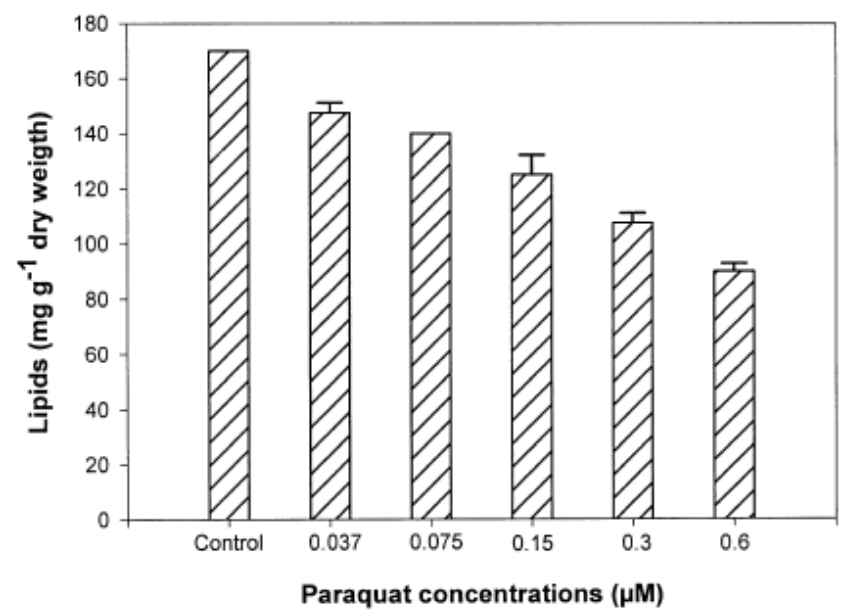

Fig. 4. Photosynthetic pigments (chlorophylls $a$ and $b$, and total carotenoids), expressed as $\mathrm{mg}$ per $\mathrm{g}$ of dry weight, obtained from cultures of Chlamydomonas eugametos exposed to different paraquat concentrations (expressed as $\mu \mathrm{M}$ ), after $96 \mathrm{~h}$

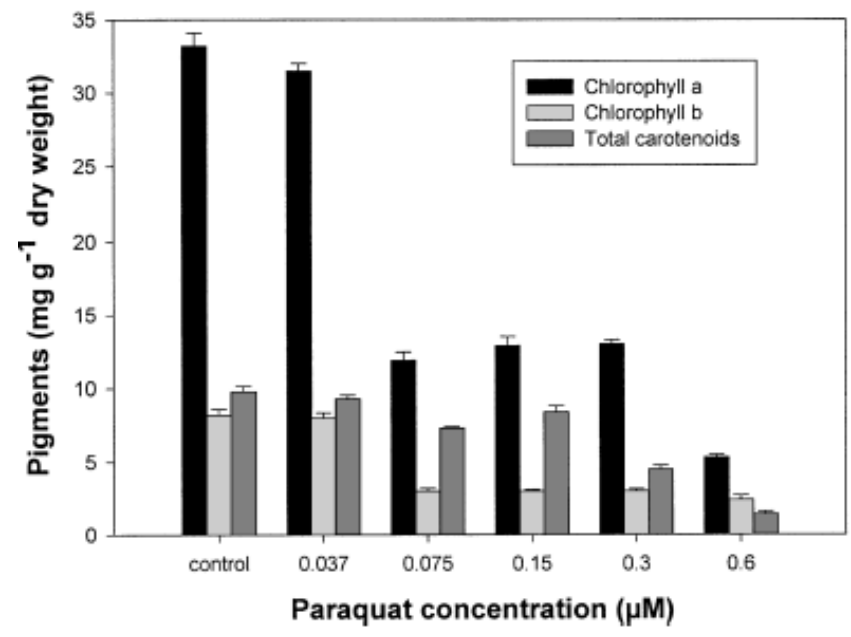

The element composition $(\mathrm{C}, \mathrm{N})$ as well as the total lipid content of the cultures were also affected when the higher doses of paraquat being tested were added. The C:N ratio is a parameter inversely correlated with the growth rate (Laws and halup 1990). Our results agree, since the C:N ratio was significantly higher, as compared with the control (4.88), in cultures with paraquat concentrations of $0.15,0.30$, and $0.60 \mu \mathrm{M}$ (Table 1).

Lipid content was particularly sensitive to paraquat, since lipid content was significantly affected at paraquat concentrations of $0.075 \mu \mathrm{M}$. The decrease in lipid content is due to lipid peroxidation, as well as to the decrease in the lipid synthesis, that is NADPH-dependent, initiated by the presence of paraquat into the cells, where this herbicide competes for the electrons of the transporting chain to the PS I level (Tissut et al. 1987; Brooks et al. 1988; Neuhaus and Stitt 1989; Mehlhron 1990; Bowler et al. 1991).

The photosynthetic pigments, chlorophyll $a$ and $b$, were affected at $0.075 \mu \mathrm{M}$ and higher paraquat concentrations. As with total lipids, the chlorophylls act as a sensitive indicator to paraquat toxicity for microalgal cells. It has been indicated that paraquat causes an oxidative degradation of chlorophyll (Kirtikara and Talbot 1996), and our results are in agreement with 
data obtained for three different chlorophytes (Scenedesmus dimorphus, Scenedesmus quadricauda, and Ankistrodesmus falcatus) exposed to paraquat for $96 \mathrm{~h}$, indicating that chlorophyll a was the most sensitive metabolic parameter assayed (Ibrahim 1990).

Cellular detoxification mechanisms involve enzymatic mechanisms (SOD, GR), as mentioned before, and nonenzymatic mechanisms; among the nonenzymatic mechanisms, vegetative cells contain substantial amounts of $\alpha$-tocopherol and carotenoids that act as nonenzymatic "rubbish bins" for oxygen radicals (Young and Britton 1990; Fryer 1992). This carotenoid protective role could explain the differences in the inhibition pattern observed with the lipids and the photosynthetic pigments chlorophyll $a$ and $b$; while the chlorophyll content shows a significant decrease at paraquat concentrations of $0.075 \mu \mathrm{M}$ or higher, the total carotenoids only show a significant inhibition when the highest herbicide concentrations are added $(0.30$ and $0.60 \mu \mathrm{M})$ and the oxidative effects brought about by the paraquat overcome the response capacity of all the cellular detoxification mechanisms.

Our study reveals that paraquat concentrations above $0.15 \mu \mathrm{M}$ are toxic for the microalga $C$. eugametos, inducing an inhibition of all the physiological parameters analyzed and strong structural changes. However, lower concentrations cause alterations in certain cellular components that are especially sensitive to the toxic action of the herbicide; so total lipids and photosynthetic pigments content are affected by concentrations such low as $0.037 \mu \mathrm{M}$. Having into account these results, these parameters are better indicators of the cellular state than data on biomass or growth rate.

\section{Acknowledgments.}

This work was supported by a grant from Consellería de Educación e Ordenación Universitaria, Xunta de Galicia (ref. XUGA10301B94). D. Franqueira holds fellowship from the Plan Nacional F.P.U., Ministerio de Educacion y Cultura, Madrid, Spain.

\section{References}

Abalde J, Cid A, Reiriz S, Torres E, Herrero C (1995) Response of the marine microalga Dunaliella tertiolecta (Chlorophyceae) to copper toxicity in short time experiments. Bull Environ Contam Toxicol 54:317-324

Blaise CR (1993) Practical laboratory applications with micro-algae for hazard assessment of aquatic contaminants. In: Richardson M (ed) Ecotoxicology monitoring. VCH, Weinheim, Germany, pp 83-107 
Bligh EG, Dyer WJ (1959) A rapid methods for total lipid extraction and purification. Can J Biochem Physiol 37:911-917

Bowler C, Slooten L, Vandenbranden S, De Rycke R, Botterman C, Sybesma C, Van Montagu $M$, Inze D (1991) Manganese superoxide dismutase can reduce cellular damage mediated by oxygen radicals in transgenic plants. EMBO 10:1723-1732

Bray DF, Bagu JR, Nakamura K (1993) Ultrastructure of Chlamydomonas reinhardtii following exposure to paraquat: comparison of wild type and a paraquat-resistant mutant. Can $\mathrm{J}$ Bot 71:174-182

Brooks A, Portis AR, Sharkey TD (1988) Effects of irradiance and methyl viologen treatment onATP, ADP, and activation of ribulose bisphosphate carboxilase in spinach leaves. Plant Physiol 88:850-853

Brown TE, Richardson FL, Vaughn ML (1967) Development of red pigmentation in C. winmeri (Chlorophyta, Chlorococcales). Phycologia 6:12-16

Cid A, Fidalgo P, Herrero C, Abalde J (1996) Toxic action of copper on the membrane system of a marine diatom measured by flow cytometry. Cytometry 25:32-36

Cid A, Herrero C, Torres E, Abalde J (1995) Copper toxicity on the marine microalga Phaeodactylum tricornutum: effects on photosynthesis and related parameters. Aquatic Toxicol 31:165-174

Devine M, Duke SO, Fedtke Ce (1993) Physiology of herbicide action. PTR Prentice-Hall, Englewood Cliffs, NJ

Fentem J, BallsM(1993) Replacement of fish in ecotoxicology testing: use of bacteria, other lower organism and fish cells in vitro. In: Richardson M (ed) Ecotoxicology monitoring. VCH, Weinheim, pp 71-81

Fryer MJ (1992) Antioxidant effects of thylakoid vitamin E (atocopherol). Plant Cell Environ 15:381-392

Hörnström E (1990) Toxicity test with algae-a discussion on the batch method. Ecotoxicol Environ Safety 20:343-353

Ibáñez M, Picó Y, Mañes J (1996) Influence of organic matter and surfactans on solid-phase extraction of diquat, paraquat and difenzopuat from waters. J ChromatogrA727:245-252

Ibrahim EA(1990) The influence of the herbicide paraquat "gramoxon" on growth and metabolic activity of three chlorophytes. Water Air Soil Poll 51:89-93

Iwasa K, Murakami S (1968) Palmelloid formation of Chlamydomonas. I. Palmelloid induction by organic acids. Physiol Plant 21:1224-1233 
Iwasa K, Murakami S (1969) Palmelloid formation of Chlamydomonas. II. Mechanism of palmelloid formation by organic acids. Physiol Plant 22:43-50

Jeffrey SW, Humphrey GF (1975) New spectrophotometric equations for determining chlorophylls a, b, c1 and c2 in higher plants, algae and natural phytoplankton. Biochem Physiol Pflanz 167:191-194

Kalayanova FP, El Batawi MA(1991) Human toxicology of pesticides. CRC Press, Boca Raton, FL

Kirtikara K, Talbot D (1996) Alteration in protein accumulation, gene expression and ascorbateglutathione pathway in tomato (Lycoper-sicon esculentum) under paraquat and ozone stress. $\mathrm{J}$ Plant Physiol 148:752-760

Landis WG, Yu M-H (1995) Introduction to environmental toxicology. Impacts of chemical upon ecological systems. Lewis Publishers, Boca Raton, FL

Laws EA, Chalup MS (1990) A microalgal growth model. Limnol Oceanogr 35:597-608

Mehlhron H (1990) Ethylene-promoted ascorbate peroxidase activity protects plants against hydrogen peroxide-ozone and paraquat. Plant Cell Environ 13:71-76

Nakamura K, Sakon M, Hatanaka MK (1976) Chemical factors affecting palmelloid-forming activity of chloroplatinic acid on Chlamydomonas eugametos. Physiol Plant 36:293-296

Neuhaus HE, Stitt M (1989) Perturbation of photosynthesis in spinach leaf discs by low concentration of methyl viologen. Planta 179:51-60

Olsen Y, Knutsen G, Lien T (1983) Characteristics of phosphorus limitation in Chlamydomonas reinhardtii (Chlorophyceae) and its palmelloids. J Phycol 19:313-319

Rabinowitch HD, Clare DA, Crapo JD, Fridovitch I (1983) Positive correlation between superoxide dismutase and resistance to paraquat toxicity in the green alga Chlorella sorokiniana. Arch Biochem Biophys 225:640-648

Reader S, Marion M, Denizeau F (1993) Flow cytometric analysis of the effects of tri-n-butyltin chloride on cytosolic free calcium and thiol levels in isolated rainbow trout hepatocytes. Toxicology 80:117-129

Saenz ME, Alberdi JL, Di Marzio WD, Accorinti J, Tortorelli MC (1997) Paraquat toxicity to different green algae. Bull Environ Contam Toxicol 58:922-928

Shapiro HM (1995) Practical flow cytometry, 3rd ed. Wiley-Lyss Inc., New York, NY

Strickland JD, Parsons TR (1972) A practical handbook of seawater analysis. Otawa, Fisheries Research Board of Canada 
Summers LA (1980) The bipyridinium herbicides. Academic Press, New York, NY

Tissut M, Ravanel P, Nurit F, Deslandres C, Bourguignon J (1987) Effects of LS82556 on thylakoid activities and photosynthesis: a comparison with paraquat and acifluorfen. Pestic Biochem Physiol 29:209-216

Vonshak A (1986) Laboratory techniques for the cultivation of microalgae. In: Richmond A (ed) Handbook of microalgal mass culture. CRC Press Inc, Boca Raton, FL, pp 117-145

Walsh GE, Merril RG (1984) Algal bioassays of industrial and energy process effluents. In: Shubert LE (ed) Algae as ecological indicators. Academic Press, London, pp 329-360

Young A, Britton G (1990) Carotenoids and stress. In: Alscher RG, Cumming JR (eds) Stress responses in plants. Adaptation and acclimation mechanisms.Wiley-Liss, New York, NY, pp 87112 